\title{
Characterisation of enzymatically oxidised lignosulfonates and their application on lignocellulosic fabrics
}

\author{
Suyeon Kim, ${ }^{\text {a }}$ Carla Silva, ${ }^{\text {a }}$ Andrea Zille, ${ }^{b}$ Carmen Lopez, ${ }^{a}$ \\ Dmitry V Evtuguin ${ }^{c}$ and Artur Cavaco-Paulo ${ }^{\mathrm{a} *}$
}

\begin{abstract}
BACKGROUND: The 'double function' of laccase, from the ascomycete Myceliophthora, to depolymerise/polymerise lignin was studied in this work. A lignosulfonate (LS) compound was oxidised by enzymatic action and several techniques were applied to measure the polymeric changes obtained. This study was focused on the attachment level of the oxidised LS at the flax surface.

RESULTS: Modified solutions were studied in terms of surface charge. Zeta potential values obtained showed an increase of polymerisation after several days of incubation. The change in molecular weight after LS polymerisation was detected using gel permeation chromatography. An increase of $1700 \mathrm{Da}$ was achieved. Fourier transform infrared and UV-visible spectroscopy techniques were applied and the results showed an increase of the degree of polymerisation. The colour strength of flax fabrics incubated with oxidised LS solutions was also measured and an increase of $K / S$ ( $K$, absorption coefficient; $S$, scattering coefficient) after enzymatic oxidation was observed.

CONCLUSION: The oxidised lignin products obtained show good potential for use in natural surface modification of textile materials containing flavonoids. These findings have important practical implications for lignocellulosic fibre coloration, where new polymers can replace harsh chemicals in the textile industry.
\end{abstract}

(c) 2009 Society of Chemical Industry

Keywords: FTIR; gel permeation chromatography (GPC); laccase; lignosulfonates; UV-visible spectroscopy

\section{INTRODUCTION}

Lignin is nature's most abundant aromatic polymer. ${ }^{1,2}$ It is a highly branched, three-dimensional phenolic polymer with a wide variety of functional groups providing active centres for chemical and biological interactions. ${ }^{3}$ Lignin is separated from wood during pulp and papermaking operations, where it serves primarily as a fuel. Only a small amount ( $1-2 \mathrm{wt} \%$ ) is isolated from spent pulping liquors and employed in a wide range of special products. ${ }^{1}$

The heterogeneity of lignin is caused by variations in the polymer composition, size, crosslinking and functional groups. ${ }^{4,5}$ Lignins vary in structure according to their method of isolation and their plant source. Plant lignins can be broadly divided into three classes: softwood (gymnosperm), hardwood (angiosperm) and grass or annual plant (graminaceous) lignin. According to the widely accepted concept, lignin may be identified as an amorphous, polyphenolic material arising from enzyme-mediated dehydrogenative polymerisation of three phenylpropanoid monomers, p-coumaryl, coniferyl and sinapyl alcohols, which are connected via carbon-carbon and ether linkages. ${ }^{6,7}$ These monolignols produce, respectively, $p$-hydroxyphenyl, guaiacyl and syringyl phenylpropanoid units when incorporated into the lignin polymers. ${ }^{3}$

Chemical pulping reactions are divided into two major categories: sulfite and sulfate pulping. Native lignin is broken down during the sulfite pulping process by cutting the randomly distributed $\alpha-O-4$ ether bonds. Lignosulfonates are the reaction products in the sulfite pulping of cellulose while kraft lignin is the reaction product in the sulfate pulping of cellulose. Nevertheless, wastewater effluents containing lignosulfonates are an environmental problem in sulfite pulping. ${ }^{8}$ Lignosulfonates have high molecular weight and contain sulfonate groups. The fragments are made water soluble by the introduction of sulfonic acid groups. The resulting lignosulfonates find widespread uses in a variety of applications such as dispersion agents. Lignin-based products are also used in other application areas such as ceramics, dispersants in textile dyeing, pesticides and binders in briquetting and animal feed. ${ }^{1,9}$ Nevertheless, the overall global structure and shape of these molecules is not well known. The characterisation of the polymeric properties of lignin is difficult due to the complexity and irregularity of the molecular structure. Extensive work has

\footnotetext{
* Correspondence to: Artur Cavaco-Paulo, University of Minho, Textile Engineering Department, 4800-058 Guimarães, Portugal. E-mail: artur@det.uminho.pt

a University of Minho, Textile Engineering Department, 4800-058 Guimarães, Portugal

b IBMC - Instituto de Biologia Molecular e Celular, Universidade do Porto, Portugal

c University of Aveiro, Chemical Department, 3810-193 Aveiro, Portugal
} 
been done characterising the molecular weight distribution of lignins. ${ }^{8,9}$

Fungal laccases (EC 1.10.3.2) are multicopper inducible oxidases, which are capable of reducing oxygen to water and simultaneously eliminating one electron from phenolic compounds to give phenoxy radicals. Because of their ability to oxidise phenolic compounds, they are considered as potential industrial enzymes in various applications, such as delignification, wood fibre modification or remediation of contaminated effluents. ${ }^{10,11}$ Laccase reacts with polyphenols and other lignin-derived aromatic compounds, which can be both polymerised and depolymerised, or act as low-molecular-weight mediators. ${ }^{12-16}$

Ishira and Miyazaki treated milled wood lignin (MWL) with laccase and found that the molecular weight was increased. ${ }^{17}$ In addition to the polymerisation, a small fraction of the MWL was also shown to be degraded to low-molecular-weight quinone structures. Those authors concluded that laccases operated in both polymerisation and depolymerisation with the former dominating. Additional evidence in favour of lignin polymerisation by laccase was revealed when the molecular weight of water-insoluble lignin increased on adding cultures of the fungus Fomes annosus. ${ }^{18}$ Work performed by Ferm et al. ${ }^{19}$ involved laccase treatment of water-soluble lignosulfonates. Not surprisingly, a browning of the lignosulfonate solutions combined with an increase in the average molecular weight was observed. Phenoxy radicals have been shown to be formed during laccase treatment of lignin model compounds and isolated lignin. It was found that the formation of phenoxy radicals is the predominant mechanism of lignin oxidation by laccase. ${ }^{19}$ Leonowicz et al. observed laccase-catalysed polymerisation of low-molecular-weight fractions and depolymerisation of high-molecular-weight fractions. ${ }^{20}$ Further evidence for the depolymerisation/polymerisation 'double function' of laccase is given in the work of Hataaka et al. ${ }^{21}$ Bae and Kim showed that laccase depolymerised large lignosulfonates at $\mathrm{pH}=4.5$; polymerisation was shown to occur at $\mathrm{pH}=6$. Hataaka et al. observed that laccase was able to depolymerise lignin preparations only if the molecular weight of the sample was less than $10000 \mathrm{~g}$ $\mathrm{mol}^{-1}$; polymerisation was shown to occur with larger molecular weight fragments. ${ }^{21}$ This contrasts with the work of Leonowicz et $a .^{20}$ who observed depolymerisation of large fragments and polymerisation of smaller ones. The ability of some ligninolytic fungi enzymes like laccase to degrade lignosulfonates has also been investigated. ${ }^{8-11}$

The main purpose of the work reported here was to produce novel polymers using laccase as a biocatalyst for lignosulfonate polymerisation. The surface charge of solutions, measured as zeta potential, was used to confirm polymerisation. At the same time UV-visible and Fourier transform infrared (FTIR) spectroscopy methods were used to monitor the modifications of the polymers obtained. The new compounds obtained after enzymatic polymerisation were applied on the surface of flax fabrics that naturally contain lignin compounds. The colour strength, measured as $K / S$ variation (where $K$ is the absorption coefficient and $S$ the scattering coefficient), of the flax samples was measured; an increase of this value was expected after deposition of the new polymers.

\section{EXPERIMENTAL}

\section{Enzyme, reagents and fabrics}

Laccase (EC 1.10.3.2) from the ascomycete Myceliophthora (Novozym ${ }^{\circledR} 51003 ; 306 \mathrm{U} \mathrm{mL}^{-1}$ at $25^{\circ} \mathrm{C}, 1667 \mathrm{U} \mathrm{mL}^{-1}$ at $50^{\circ} \mathrm{C}$ ) was obtained from Novozymes (Bagsvaerd, Denmark). The sulfonated lignin compound isolated from softwood (DP398; calcium lignosulfonate) was kindly supplied by Borregaard-LignoTech (Sarpsborg, Norway). Its structure is shown in Fig. 1 . The $100 \%$ raw woven flax fabrics having 14/14 yarns (warp/weft) per centimetre, kindly supplied by the Institute of Natural Fibres (Poland), were used for

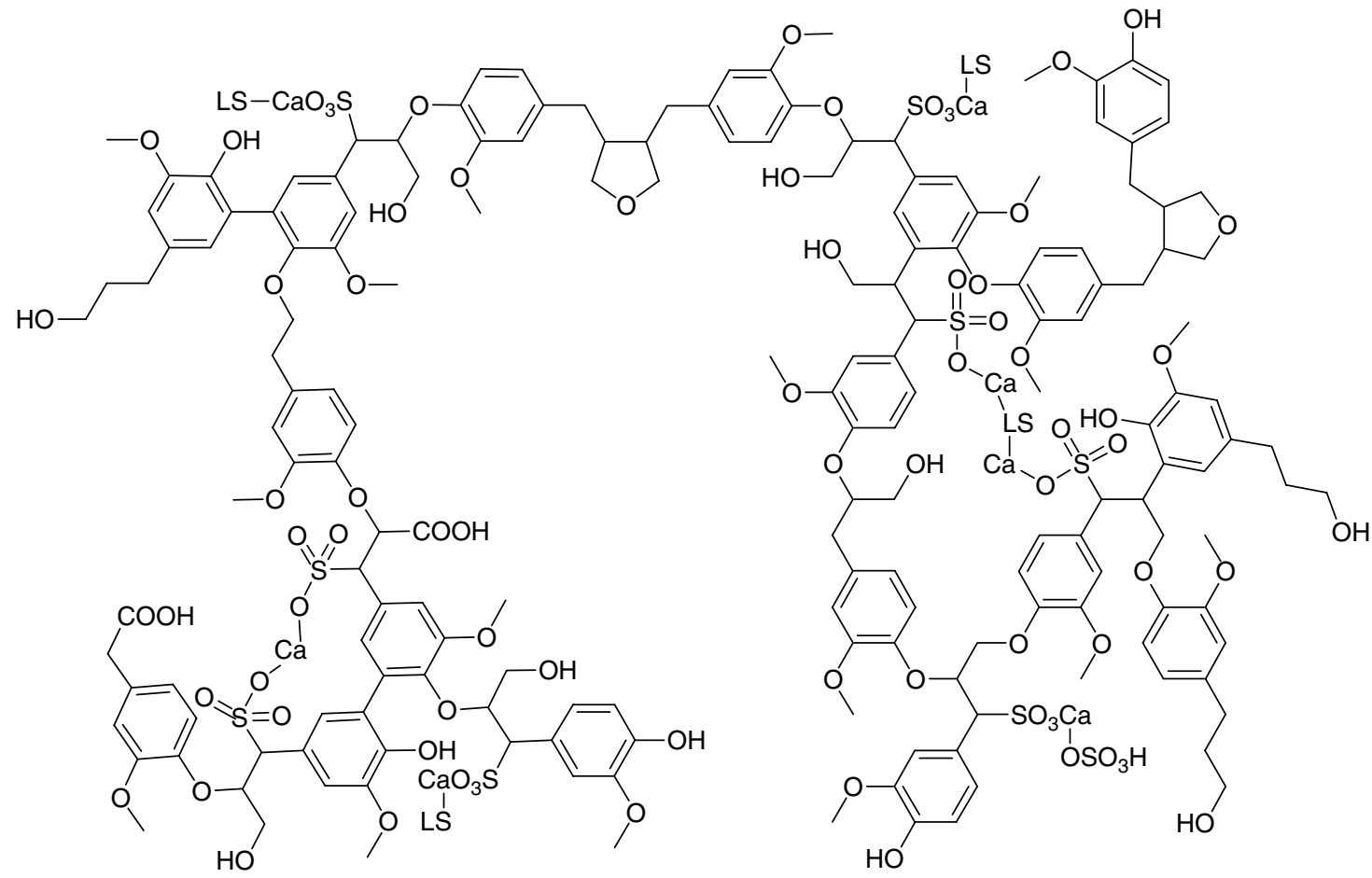

Figure 1. Structure of softwood calcium DP398. 
coloration using lignosulfonate solutions oxidised with laccase. The other chemicals or materials used in this study were purchased from Sigma (St Louis, USA), and were used without further purification.

\section{Enzymatic oxidation of lignosulfonate using laccase}

For enzymatic oxidation, a lignosulfonate compound $\left(2 \mathrm{~g} \mathrm{~L}^{-1}\right)$ was prepared with a filtered $0.1 \mathrm{~mol} \mathrm{~L}^{-1}$ acetate buffer at $\mathrm{pH}=5$. The lignosulfonate solution prepared $(100 \mathrm{~mL})$ was incubated using a water bath at $50{ }^{\circ} \mathrm{C}$ with orbital agitation ( $80 \mathrm{rpm}$ ). The conditions, such as $\mathrm{pH}$ and temperature, were set up considering the optimum activity of laccase. Laccase $\left(0.6 \mathrm{U} \mathrm{mL}^{-1}\right)$ was added uniformly in the prepared lignosulfonate solutions.

\section{UV-visible spectral analysis}

To monitor the reorganisation of the lignosulfonate compound by enzymatic oxidation, the spectra of prepared solutions were measured using a diode-array J\&M Tidas UV-visible spectrophotometer (J\&M Analytische Mess und Regeltechnik GmbH, Germany) before and after enzymatic treatment.

\section{Zeta potential determinations}

The surface charge of oxidised solutions was measured in terms of zeta potential using a Zetasizer Nano Series (Malvern Instruments Inc., Worcester, UK). This method measures how fast a particle moves in a liquid when an electrical field is applied-i.e. its velocity. The aggregation behaviour of lignosulfonate particles in solution with laccase was therefore investigated by determining the electrophoretic mobility.

\section{SEC analysis}

SEC analysis was carried out using two PL aquagel-OH MIXED $8 \mu \mathrm{m}$ $300 \times 7.5 \mathrm{~mm}$ columns protected by a PL aquagel-OH Guard $8 \mu \mathrm{m}$ pre-column in a PL-GPC 110 system (Polymer Laboratories, UK). The columns, injector system and the detector (RI) were maintained at $36^{\circ} \mathrm{C}$ during the analysis. Lignosulfonate was dissolved in $0.1 \mathrm{~mol} \mathrm{~L}^{-1} \mathrm{NaNO}_{3}$ aqueous solutions to a concentration of about $0.5 \mathrm{wt} \%\left(5 \mathrm{mg} \mathrm{mL}^{-1}\right)$. The eluent $\left(0.1 \mathrm{~mol} \mathrm{~L}^{-1}\right.$ aqueous solution of $\mathrm{NaNO}_{3}$ ) was pumped at a flow rate of $0.9 \mathrm{~mL} \mathrm{~min}-1$. The analytical columns were calibrated with sulfonated lignin model compounds and poly(sodium styrene sulfonate) (PSSNa) standards (Pressure Chem. Comp.) in the range $0.2-10 \mathrm{kDa}$.

\section{Coloration of lignocellulosic fabrics (flax) with oxidised lignosulfonate solutions and estimation of colour strength}

All the samples used for coloration were submitted to an alkaline scouring pre-treatment. Without adding other chemicals, coloration with oxidised lignosulfonate solutions $\left(5 \mathrm{~g} \mathrm{~L}^{-1}\right)$ was carried out using $150 \mathrm{~cm}^{3}$ capacity sealed stainless steel dyepots, housed in a dyeing machine (AHIBA Spectradye, from Datacolor). Coloration was performed at $90^{\circ} \mathrm{C}$ and $40 \mathrm{rpm}$ for $1 \mathrm{~h}$. As a control, coloration was carried out with lignosulfonate solutions without enzymatic treatment. After coloration, a washing process was performed three times with Lutensol AT25 solution $\left(1 \mathrm{~g} \mathrm{~L}^{-1}\right)$ at boiling temperature to remove uncoupled polymers and residual enzyme from the fabric surface. The bath ratio was set at 1:20 (fabric to liquor) in the coloration and washing processes.

Colour strengths of the fabrics were determined using a Spectraflash 600 (Datacolor) reflectance measuring apparatus with standard illuminant D65 (LAV/Spec. Excl., d/8, D $65 / 10^{\circ}$ ). The colour strength was evaluated as $K / S$ at maximum absorption wavelength $(360 \mathrm{~nm})$. The ratio between $K$ and $S$ is related to reflectance data by applying the Kubelka-Munk law at each wavelength, and it is proportional to dye concentration. ${ }^{22,23}$ Each sample was measured five times and averaged data were obtained automatically using the apparatus. All measurements were performed using at least triplicate samples.

\section{FTIR spectroscopy}

FTIR spectra were obtained with a Perkin Elmer infrared spectrophotometer. Before collection, background scanning was performed using $\mathrm{KBr}$ powder. The oxidised lignosulfonate samples, previously lyophilised, were mixed with a small amount of $\mathrm{KBr}$ that was used as matrix. At least 32 scans were obtained to achieve an adequate signal-to-noise ratio. The spectra were obtained in the region of $450-4000 \mathrm{~cm}^{-1}$ with a resolution of $8 \mathrm{~cm}^{-1}$ at room temperature.

\section{RESULTS AND DISCUSSION}

\section{UV-visible spectroscopy characterisation}

UV-visible spectra were obtained to monitor the modifications occurring to the lignin compound before and after enzymatic oxidation. The significant absorption band appearing near $280 \mathrm{~nm}$ has been frequently cited as supporting the presence of guaiacyl, syringyl and related structures with a predominance of aromatic methoxyl over aromatic hydroxyl groups. ${ }^{24}$

The samples of lignosulfonates without laccase and the samples at zero time present a band at $370 \mathrm{~nm}$. After 1 and 7 days of incubation with laccase, the lignosulfonate compound shows a shift of the band at $370 \mathrm{~nm}$ to $390 \mathrm{~nm}$. This behaviour is probably related to the polymerisation of several molecules.

In Fig. 2, the increased area of the absorption band, after laccase oxidation, is generally observed and might be related to the polymerisation event. An interesting sharp band appears after 1 day of incubation at $650 \mathrm{~nm}$. Based on the literature this can be explained by the degradation of the molecules into smaller fragments that, by laccase action, can reorganise and polymerise, increasing the colour of the solution. ${ }^{25}$

\section{Molecular weight: SEC analysis}

It is most likely that lignosulfonate DP398 during the treatment with laccase undergoes both partial depolymerisation and

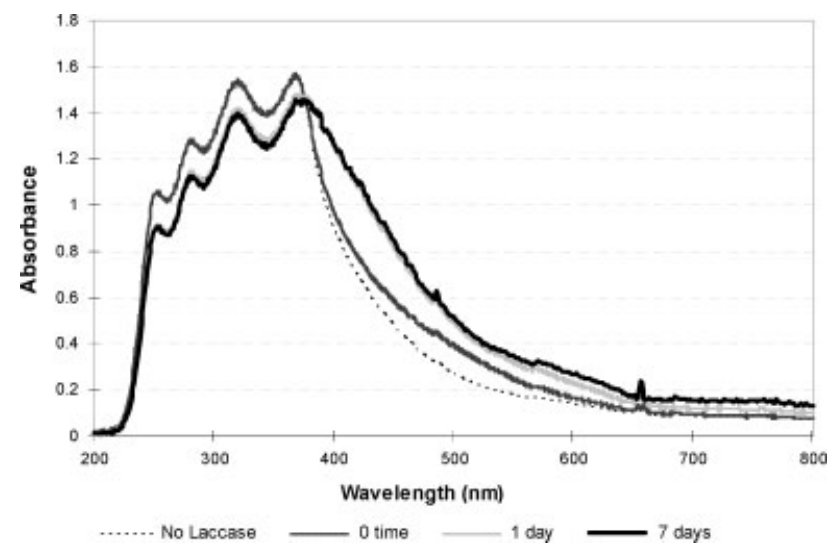

Figure 2. UV-visible spectra of lignosulfonate $\left(5 \mathrm{~g} \mathrm{~L}^{-1}\right)$ incubated without and with laccase $\left(0.6 \mathrm{U} \mathrm{mL}^{-1} ; \mathrm{pH}=5\right.$, temperature $\left.=50^{\circ} \mathrm{C}\right)$. Incubations were performed during 7 days. 


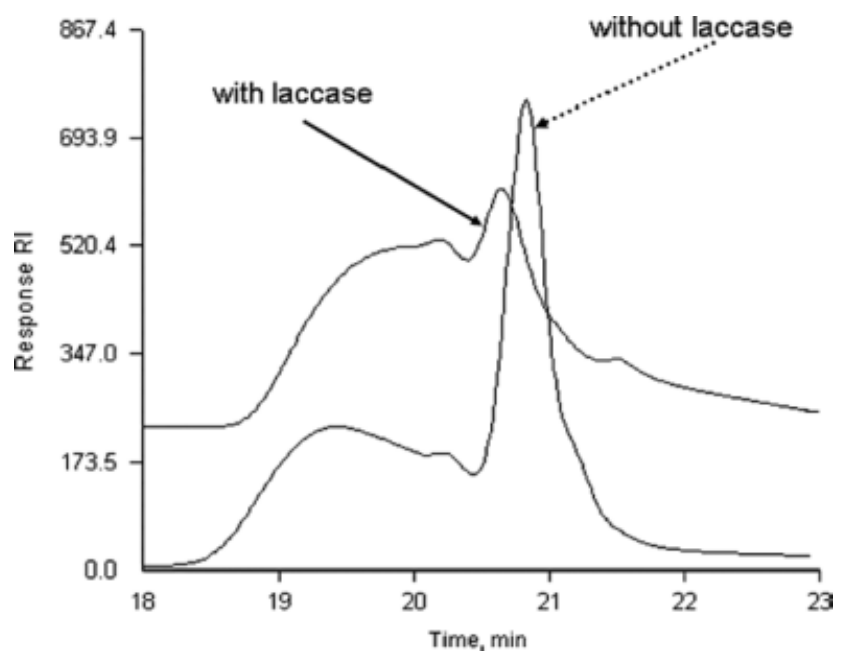

Figure 3. Molecular weight change of lignosulfonate (DP398) solution $\left(2 \mathrm{~g} \mathrm{~L}^{-1}\right)$ during 6 days of incubation with laccase $\left(0.6 \mathrm{U} \mathrm{mL}^{-1} ; \mathrm{pH}=\right.$ 5 acetate buffer; temperature $=50^{\circ} \mathrm{C}$; bath with orbital agitation). All measurements were performed using gel permeation chromatography.

polymerisation. This leads to the simultaneous appearance in the SEC curve (Fig. 3) of elution peaks at $20.8 \mathrm{~min}$ (ca $260 \mathrm{Da}$ ) and at $19.3 \mathrm{~min}$ (ca $14700 \mathrm{Da}$ ). The resulting weight-average molecular weight is increases from 5250 Da for the DP398 compound to 6950 Da for DP398 incubated with laccase for 7 days, as determined in the elution time interval of $18-22 \mathrm{~min}$.

\section{Zeta potential}

During 7 days of incubation, measurement of zeta potential was performed using the Zetasizer Nano Series. The values obtained for lignosulfonate DP398 after enzymatic oxidation are shown in Fig. 4.

The charge distribution at the surface of the polymers was obtained by measuring the zeta potential of the oxidised samples at different periods of incubation. This parameter allows us to predict the stability of the particles in solution. The results obtained show an increase of the surface charge, close to zero, which

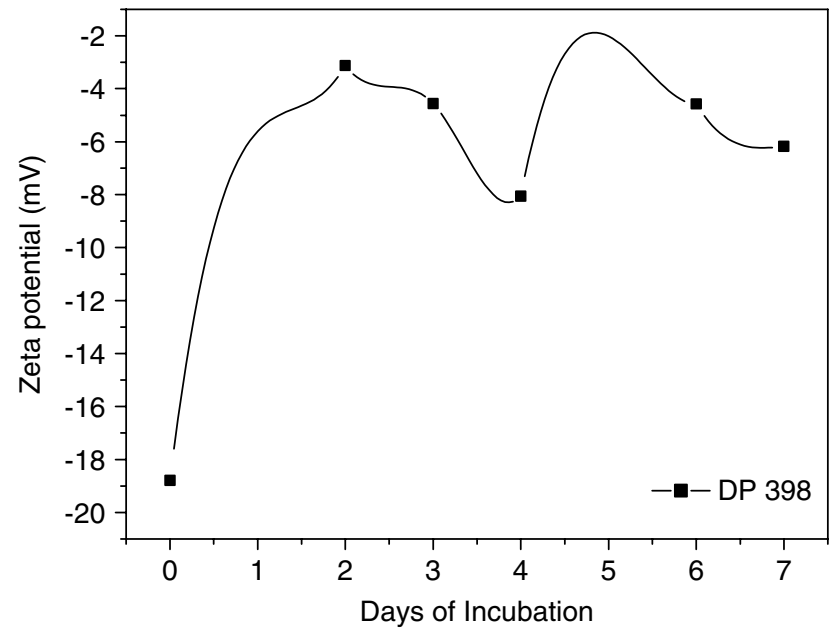

Figure 4. Zeta potential values for lignosulfonate solution $\left(2 \mathrm{~g} \mathrm{~L}^{-1}\right)$ during 7 days of incubation with laccase $\left(0.6 \mathrm{U} \mathrm{mL}^{-1} ; \mathrm{pH}=5\right.$ acetate buffer; temperature $=50^{\circ} \mathrm{C}$; bath with orbital agitation). All measurements were performed using a Zetasizer. can be related to the aggregates formed by laccase oxidative polymerisation. This aggregation results from the loss of sulfonic groups present in the structure (Fig. 1) which can lead to lower solubility. The 'double function' of laccase is quite clear when analysing these results. Despite the tendency of the values to approximate to zero, the results obtained have a significant variation. The depolymerisation/polymerisation phenomena can occur at different periods of incubation and the products formed can have different sizes and charge distributions. Moreover, the degradation products resulting from laccase catalysis can vary and not be easily detectable.

Based on work performed by others, ${ }^{26}$ we can state that laccase reacts with the oxidised lignin molecules and catalyses the formation of carboxylic acids and $o$ - and $p$-quinones by depleting high-kappa pulps primarily of C-5 phenolic groups as well as of side-chain aliphatic hydroxyl groups.

In the presence of phenolic compounds, the rate of loss of activity of laccase is clearly low, which was shown by Mai et al. ${ }^{27}$ The work of those authors proved that an increase of activity occurs in the presence of some phenolic compounds such as lignin sulfonate, phloroglucinol and guaicol after the first three days of incubation with laccase. ${ }^{28}$ By this reason, in the case of long periods of incubation, the stabilisation and activation of laccase are supported by the phenolic compounds which are partially degraded from the residual lignosulfonate. The laccase remains stable and able to catalyse the polymerisation reaction for a long period of incubation.

In the reaction of the solution of lignosulfonate, laccase catalyses one-electron oxidation which involves the formation of a free cation radical of substrate after the transfer of a single electron to laccase; the radicals can further react in non-enzymatic oxidation..$^{29,30}$ The radicals, which are relatively stable owing to electron delocalisation that provides single electron density to the side-chain $\beta$-position, are coupled. ${ }^{3,4}$

\section{FTIR spectroscopy}

The oxidised lignosulfonate samples and the respective controls, previously lyophilised, were studied using FTIR spectroscopy. The results presented in Fig. 5 show that the band at $3400 \mathrm{~cm}^{-1}$, commonly present for all samples and attributed to the hydroxyl groups in lignin, ${ }^{2}$ has a lower absorption intensity after incubation with laccase. This might be caused by the laccase-catalysed oxidation reaction. The band at $3000-2800 \mathrm{~cm}^{-1}$ corresponding to the region of the $\mathrm{C}-\mathrm{H}$ stretch of methyl and methylene groups,

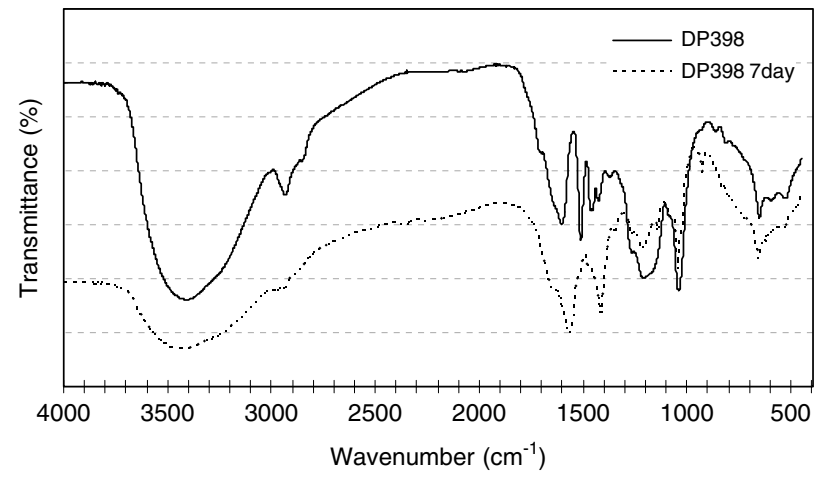

Figure 5. FTIR spectra of lignosulfonate samples treated without and with laccase $\left(0.6 \mathrm{U} \mathrm{mL}^{-1}\right)$ for 7 days $(\mathrm{pH}=5$ acetate buffer; temperature = $50{ }^{\circ} \mathrm{C}$; bath with orbital agitation). 
which is mainly attributed to methoxyl groups, is observed for control samples and tends to disappear for the samples incubated with laccase. Other authors have already shown that lignin oxidases catalyse several oxidations in the alkyl side chains of ligninrelated compounds, $\mathrm{C}-\mathrm{C}$ cleavages in the side chains of lignin subunits, oxidation of veratryl alcohols and related substances to aldeydes or ketones, intradiol cleavage of phenylglycol structures and hydroxylation of benzylic methylene groups. ${ }^{31}$

The four bands at $1600-1510 \mathrm{~cm}^{-1}$, representative of aromatic skeletal vibrations, are present for all control compounds; however, after 7 days of incubation, laccase oxidation leads to the appearance of two large peaks at this band region. The polymerisation achieved after this long period of incubation is translated into the formation of bigger aggregates and the presence of small polymers is not easily detectable.

The results show a marked decrease of the intensity of the band corresponding to the $\mathrm{S}=\mathrm{O}$ groups $\left(1174-1222 \mathrm{~cm}^{-1}\right)$. The oxidation promoted by laccase implies a degradation reaction with the loss of functional groups from the lignin compounds. These results are also confirmed by the zeta potential measurements.

Between 1300 and $1000 \mathrm{~cm}^{-1}$, the bands and peak ratios are very different due to the various vibrational modes such as $\mathrm{C}-\mathrm{O}, \mathrm{C}-\mathrm{H}$ and $\mathrm{C}=\mathrm{O}$. All the samples present this peak; however, the oxidised lignosulfonate samples showed lower intensity absorption. The aggregates formed by polymerisation might increase the steric hindrance and hamper the detection of the small groups. ${ }^{5}$ In the spectra obtained, a new peak is detected at $920 \mathrm{~cm}^{-1}$ related to the $\mathrm{C}-\mathrm{C}$ stretch of aliphatic chains obtained after oxidation by laccase.

The distinct band appearing around $640 \mathrm{~cm}^{-1}$ is assigned to the stretching vibration of sulfonic groups $(\mathrm{S}-\mathrm{O})$. Analysing the spectra obtained for all the oxidised lignosulfonate samples, a small variation of the peak intensity can be observed. This might be explained by the laccase-catalysed oxidation reactions occurring, causing degradation and consequently loss of sulfonic functional groups.

\section{Estimation of colour strength}

The lignosulfonate compound oxidised for 1 and 7 days by laccase was applied on scoured flax fabric which naturally contains lignin compounds at the surface. The coloration was estimated using $\mathrm{K} / \mathrm{S}$ measurements to confirm the interrelation between lignin compounds in the differently incubated reaction solutions and lignin existing on the fabric surface. ${ }^{32,33}$ As shown in Fig. 4 (zeta potential values), the polymerisation markedly increased after 2 days of incubation with laccase. The samples were afterwards colourised with lignosulfonate solutions corresponding to both periods of molecular weight changes (depolymerisation: 1 day; polymerisation: 7 days).

The colour strength is quite low due to the concentration of the reaction solutions prepared, which was only $5 \mathrm{~g} \mathrm{~L}^{-1}$. This concentration is considered low due to the fact that it is not strong enough to cover the intense colour of the scoured flax fabrics. The flax fabric samples colourised with the lignosulfonate solutions show an increase of colour adsorption which is more pronounced when solutions oxidised for 7 days are used (Fig. 6). These solutions present a higher level of polymer production, these polymers having a greater ability to undergo coupling reactions with the natural lignin present at the surface of the flax fabrics. A correlation between the level of the attached lignosulfonate compound and the level of colour intensity was obtained. The $\mathrm{K} / \mathrm{S}$

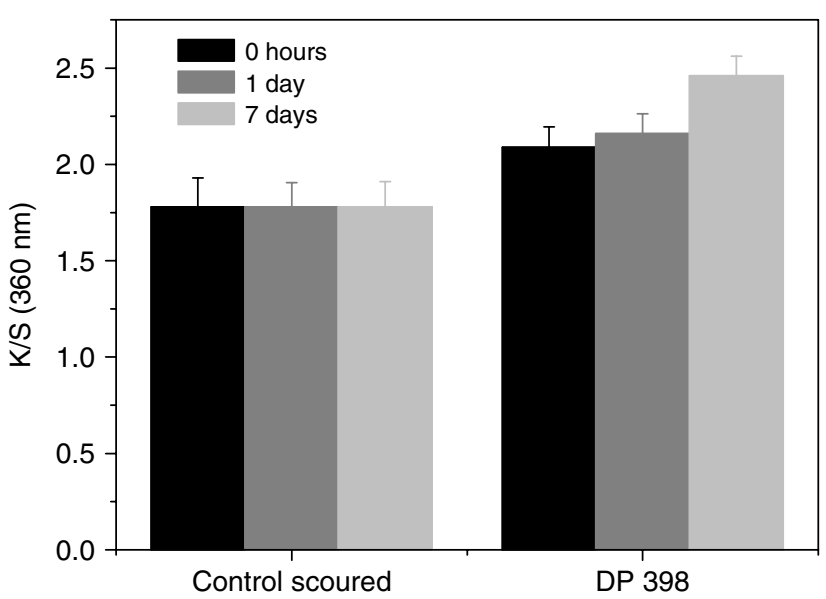

Figure 6. $K / S$ estimation of flax samples coloured with oxidised lignosulfonate solutions $\left(5 \mathrm{~g} \mathrm{~L}^{-1}\right.$; temperature $=90^{\circ} \mathrm{C} ; 1 \mathrm{~h}$; Ahiba machine at $40 \mathrm{rpm})$.

increase is directly related to the amount of polymer at the surface of the fabrics.

\section{CONCLUSIONS}

The results presented in this work confirm that laccase preferentially polymerises lignosulfonates by coupling of the phenoxy radicals produced by oxidation of lignin phenolic groups. It has been suggested that laccase possesses both polymerisation and depolymerisation activities for some preparations of lignosulfonates. A first stage of depolymerisation was observed followed by a period of polymerisation. The effect of phenolic compounds in lignin on the long-term stability of laccase in aqueous solution was also observed.

Laccase provides an environmentally benign process of polymer production that can be applied to the surface of flax fabrics. A synergistic effect between lignin-based polymers formed and the lignin groups at the surface of flax fabrics increases the coupling reactions resulting in a higher level of coloration. This natural process can be used as a replacement to conventional dyeing processes of lignocellulosic fabrics.

\section{REFERENCES}

1 Lora JH and Glasser WGJ, Polym Environ 10:39-48 (2002).

2 El Mansouri N and Salvadó J, Ind Crops Prod 26:116-124 (2007).

3 Boerjan W, Ralph J and Baucher M, Annu Rev Plant Biol 54:519-546 (2003).

4 Önnerud H, Zhang L, Gellerstedt $\mathrm{G}$ and Henriksson G, Plant Cell 14:1953-1962 (2002).

5 Gosselink RJA, Abächerli A, Semke H, Malherbe R, Käuper P, Nadif A, et al, Ind Crops Prod 19:271-281 (2004).

6 Boeriu CG, Bravo D, Gosselink RJA and van Dam JEG, Ind Crops Prod 20:205-218 (2004).

7 Lin SY and Dence CW, Methods in Lignin Chemistry, Springer Series in Wood Science. Springer-Verlag, Berlin (1992).

8 Eugenio ME, Carbajo JM, Terrón MC, González AE and Villar JC, Bioresour Technol 99:4929-4934 (2008).

9 Ekeberg D, Gretland KS, Gustafsson J, Bråten S and Fredheim GE, Anal Chim Acta 565:121-128 (2006).

10 Cho NS, Shin WS, Jeong SW and Leonowicz A, Bull Korean Chem Soc 25:1551 - 1554 (2004).

11 Widsten P and Kandelbauer A, Enzyme Microb Technol 42:293-307 (2008).

12 Leonwicz A, Cho NS, Luterek J, Wilkolazka A, Wojtas-Wasilewska M, Matuszewska A, et al, J Basic Microbiol 41:185-227 (2001). 
13 Bourbonnais R, Paige MG, Reid ID, Lanthier P and Yaguchi M, Appl Environ Microbiol 61:1876-1880 (1995).

14 Srebotnik E and Hammel KE, J Biotechnol 81:179-188 (2000).

15 Mita N, Tawaki S, Uyama H and Kobayashi S, Macromol Biosci 3:253-257 (2003)

16 Mai C, Schormann W, Hütterman A, Kappl Rand Hüttermann J, Enzyme Microb Technol 30:66-72 (2002).

17 Ishira T and Miyazaki M, J Jpn Wood Res Soc 18:415-419 (1972).

18 Huttermann A, Herche C and Haars A, Int J Biol Chem Phys Technol Wood 34:64-66 (1980).

19 Ferm R, Kringstad KP and Cowling EB, JColloid Interface Sci 75:859-864 (1972).

20 Leonowicz A, Szklarz G and Wojta-Wasilewska M, Phytochem Lett 24:393-396 (1985)

21 Hataaka A, Mettala A, Toikka B and Brunow G, in Biotechnology in the Pulp and Paper Industry. Proceedings of the Vienna ACS, pp. 333-340 (1996).

22 Harold RW, Textile Chem Color 19:23-31 (1987).
23 McDonald R, Colour physics for industry. Society of Dyers and Colourists, UK (1987).

24 Wexler AS, Anal Chem 36:213-221 (1964)

25 Oakes J and Gratton P, J Chem Soc 2:1857-1864 (1998).

26 Chakar FS and Ragauskas AJ, Sixth European Workshop on Lignocellulosics and Pulp, series no. 876, France (2000).

27 Mai C, Schormann W, Milstein O and Huttermann A, Appl Microbiol Biotechnol 54:510-514 (2000).

28 Russell WR, Forrester AR, Chesson A and Burkitt M, Arch Biochem Biophys 332:357-366 (1996).

29 Johannes C and Majacherczyk A, J Biotechnol 78:193-199 (2000).

30 Soares MB, Pessoa Amorim MT, Oliveira AM, Hrdina R and CostaFerreira M, Enzyme Microb Technol 30:607-612 (2002).

31 Tien M and Kirk TK, Methods Enzymol 161:661-663 (1983).

32 Kim SY, Lopez C and Cavaco-Paulo A, Eng Life Sci 8:1-8 (2008).

33 Kim SY, Moldes D and Cavaco-Paulo A, Enzyme Microb Technol 40:1788-1793 (2007) 